\section{Anticoagulation therapy in the elderly with non-valvular atrial fibrillation: a double-edged sword}

\author{
Francesco Vetta, ${ }^{1}$ \\ Gabriella Locorotondo, 1,2 \\ Giampaolo Vetta ${ }^{1,3}$
}

${ }^{1}$ Cardiology Unit, Israelite Hospital, Rome; ${ }^{2}$ Institute of Cardiology, Catholic University of the Sacred Heart, Rome; ${ }^{3}$ Institute of Cardiology, Campus Bio-Medico University, Rome, Italy

I am tomorrow what I establish today. I am today what I established yesterday... J. Joyce

\begin{abstract}
Prevalence of non-valvular atrial fibrillation is increasing over time. Particularly in elderly population, treatment strategies to reduce the rate of stroke are challenging and still represent an unsolved cultural question. Indeed, the risk of thromboembolism increases in the elderly in parallel with the risk of bleeding. The frequent coexistence of several morbidities, frailty syndrome, polypharmacy, chronic kidney disease and dementia strengthens the perception that risk-benefit ratio of anticoagulant therapy could be unfavorable, and explains why such treatment is underused in the elderly. Recently, the introduction of non-vitamin $\mathrm{K}$ oral anticoagulants (NOACs) has allowed us to overcome the large number of limitations imposed by the use of vitamin $\mathrm{K}$ antagonists. In this manuscript, the benefits of individual NOACs in comparison with warfarin in elderly patients are reviewed. Targeted studies on complex elderly patients are needed to test usefulness of a geriatric comprehensive assessment, besides the scores addressing risk of thromboembolic and hemorrhagic events. In the meantime, it is mandatory that use of anticoagulant therapy in most elderly people, currently excluded from randomized controlled trials, is prudent and responsible.
\end{abstract}

\section{Introduction}

Atrial fibrillation (AF) is the most common cardiac arrhythmia, with an estimated lifetime risk of $25 \%$. Its prevalence grows with age: it is less than $0.1 \%$ in subjects aged $\leq 55$ years and progressively increases up to $9-10 \%$ in subjects aged $\geq 80$ years. In 2010, in the European Union, there were 8.8 million of adults with $\mathrm{AF}$ and such prevalence is projected to increase to 17.9 million cases in $2060 .{ }^{1,2} \mathrm{AF}$ is associated to a four to five-fold increased risk of embolic stroke: this risk is estimated to rise of 1.45fold per decade of age. In fact, the ischemic stroke is expected to occur in $14 / 1000$ persons/year and 29/1000 persons/year, respectively in subjects aged between 75 and 84 years and in those of 85 years or older. ${ }^{3,4}$ Its high incidence is partly explained by the age-related prevalence of several diseases that are recognized as risk factors both for stroke and for $\mathrm{AF}$, such as hypertension, heart failure and renal failure. Almost $25 \%$ of all ischemic strokes in patients over 80 years of age are attributable to AF. Oral anticoagulant therapy (OAT) with vitamin-K antagonists (VKAs) in patients with $\mathrm{AF}$ reduces the risk of ischemic stroke by $64 \%$ : by taking into account the higher incidence of stroke in the elderly than in younger patients, it finally results in an absolute risk reduction greater in the former than in the latter..$^{1-5}$

On the other hand, aging is also associated with an increased risk of major bleedings, especially in case of OAT. The risk of hemorrhagic events related to OAT is agedependent and increases of about $40 \%$ for decade of life. Bleeding, particularly cerebral hemorrhage, is the most feared complication of OAT. Regardless of the category of anticoagulant, aging is an independent risk factor for bleeding with anticoagulation levels both in the therapeutic range and, chiefly, outside the therapeutic range, as widely demonstrated with VKAs. ${ }^{2,5}$ The annual risk of major bleeding in patients treated with VKAs is estimated at 2-3\%, while the rate of minor bleeding is $14 \%{ }^{2,6}$ Thus, concern about the bleeding risk of anticoagulants largely contributes to the underuse of VKAs in patients with AF. Surveys from Europe and North America have consistently shown that VKAs are used in only $50-60 \%$ of patients having indication to $\mathrm{OAT}^{7}$ As noteworthy, the major challenge in the elderly receiving VKAs is to ensure adequate time in therapeutic range (TTR).

Basing on such considerations, the main goal of AF treatment in the elderly should be reaching the utmost benefit in terms of ischemic stroke reduction, by minimizing the risk of harmful events. As detailed below, it may stem only from adequate knowledge of conditions in which OAT in the elderly represents a real advantage.
Correspondence: Francesco Vetta, Cardiology Unit, Israelite Hospital, via Fulda 14, 00100 Rome, Italy. Tel.: +39.06.65589369 - Fax: +39.06 .65589385 .

E-mail: vettaaritmologia@gmail.com

Key words: Atrial fibrillation; non-vitamin K antagonist oral anticoagulation; warfarin; elderly; stroke; hemorrhage; frailty.

Conflict of interest: the authors declare no potential conflict of interest.

Received for publication: 4 November 2016. Revision received: 22 April 2017.

Accepted for publication: 15 June 2017.

This work is licensed under a Creative Commons Attribution-NonCommercial 4.0 International License (CC BY-NC 4.0).

(C) Copyright F. Vetta et al., 2017

Licensee PAGEPress, Italy

Geriatric Care 2017; 3:6371

doi:10.4081/gc.2017.6371

\section{Oral anticoagulants in the elderly:} is there a net clinical benefit?

As risk of stroke grows with aging, efficacy of OAT in reducing ischemic cerebrovascular events increases in the elderly. Several comorbidities, which are known to occur more frequently in the last decades of life, further enhance the progressive risk of cardio-embolic stroke related to aging. Enlightening data from real world registries point out that the prevalence of frailty and multimorbidity ( $>3$ diseases) accounts for $50 \%$ and $71 \%$, respectively, in elderly patients hospitalized for AF. ${ }^{8}$ Consequently, as showed by Atrial Fibrillation Investigators' data, the coexistence of comorbidities enhances the benefits of OAT, especially in patients aged $\geq 75$ years. ${ }^{9}$

On the other hand, advanced age is also associated with a progressive increase in the risk of major bleeding, with a hazard ratio that is more than tripled in subjects aged $\geq 85$ years, compared to those aged $\leq 60$ years, particularly if treated by OAT. ${ }^{10,11}$ Indeed, although Warfarin is widely regarded as the cornerstone of therapy for cardioembolic stroke prevention, the related risk of bleeding is not negligible: a meta-analysis on antithrombotic therapy to prevent stroke in patients with non valvular atrial fibrillation (NVAF) showed that Warfarin therapy is associated to an annual incidence of major bleedings which varies from 1.7 to $3 \%$ in patients aged $<75$ years and from 4.2 to $5.2 \%$ in those aged $\geq 75$ years. $^{12}$

The increased risk of bleedings and 
other safety concerns, about frailty, multidrug therapy, pharmacological interactions, dementia and tendency to falls, overall represent the main reasons why physician are reluctant to undertake anticoagulation or prone to discontinue such therapy in the elderly. This behavior explains why only a low percentage of elderly patients with NVAF takes OAT. ${ }^{8-10}$ Indeed, it has been demonstrated that the use of OAT in patients with AF decreases progressively with age, from a prevalence of about twothirds in patients aged $\leq 75$ years to about $50 \%$ in those aged $>75$ years. ${ }^{13}$ Notably, a prospective cohort study has unequivocally confirmed that OAT is frequently denied to frail patients. ${ }^{14}$ Frailty and dementia are major determinants in the exclusion of elderly patients from OAT, but observational findings suggest that paradoxically the frail patient may take the utmost advantage from anticoagulation. Indeed, in the previously cited study, frail patients have been clearly shown at higher risk of stroke (HR 3.5) and mortality (HR 2.8) at six-month follow-up, when compared to non-frail patients. ${ }^{11}$

As confirmation of the advantage of OAT in the elderly, despite concerns to prescribe it, literature data actually support a net clinical benefit in the use of warfarin, especially in this age group. Results from the Swedish AF Cohort Study, indeed, clearly demonstrate that the benefit of anticoagulation with warfarin in terms of reduction of ischemic stroke, intracranial hemorrhage ( $\mathrm{ICH})$ and overall mortality, when compared to antiplatelet therapy or no antithrombotic therapy, tends to increase in parallel to both thromboembolic (quantified by the Congestive Heart Failure, Hypertension, Age $\geq 75$ doubled, Diabetes, Stroke doubled - Vascular disease, Age 65-74 and female Sex, $\mathrm{CHA}_{2} \mathrm{DS}_{2}$-VASC score) and hemorrhagic (quantified by the Hypertension, Abnormal renal/liver function, Stroke - Bleeding history or predisposition, Labile INR, Elderly $>65$ years, Drug/alcohol concomitantly, HAS-BLED score) risks. ${ }^{15}$ Furthermore, the AnTicoagulation and Risk factors In Atrial fibrillation (ATRIA) study, which involved more than 13000 AF patients, showed that the net clinical benefit of OAT raises with both age and Congestive heart failure, Hypertension, Age $\geq 75$, Diabetes, Stroke $\left(\mathrm{CHADS}_{2}\right)$ score. Adjusted net clinical benefit, indeed, was highest for patients aged $\geq 85$ years $(2.34 \%$ per year $)$ : it increased from zero in $\mathrm{CHADS}_{2}$ scores $0-1$ up to $2.22 \%$ per year in $\mathrm{CHADS}_{2}$ categories 4-6. Peaking of net clinical benefit occurred from the age of 75 years, regardless of weighting factor for ICH. ${ }^{16}$ Results from several Italian registries have further confirmed the net clinical benefit of OAT in the elderly. In a retrospective cohort observational study on 980 patients with mean age 83 years, ischemic and hemorrhagic stroke occurred in $12.3 \%$ and $1.3 \%$ of patients, respectively, and major bleedings in $4.4 \%$ of patients: use of VKA was independently associated with reduced mortality and with a non-significant reduction in incidence of ischemic stroke, without excess in bleeding risk. ${ }^{17}$ No clear gender related differences have been found in elderly patients with AF about risk of major adverse events: in a large, multicenter observational study including 4093 elderly patients who started VKA treatment after the age of 80 years, elderly males showed a higher rate of bleeding complications, and females showed a slightly higher rate of stroke, thus suggesting the possibility of a higher net clinical benefit of anticoagulant treatment in females. ${ }^{18}$

Therefore, basing on literature data, it is strikingly evident that OAT is associated to a net clinical benefit, which increases with age. The elderly earn the utmost advantage from OAT, mainly when cerebrovascular dementia can be supposed deriving from multiple cardio-embolic ischemic strokes. Nevertheless, all conditions predisposing to increase bleeding risk of OAT in the elderly should be adequately acknowledged in order to promote a conscious use of anticoagulation in such special population, which, in other words, means a careful tailoring of OAT on the individual patient. Particularly, the agerelated safety profile of different anticoagulants, which is described below, should be taken into account in order to address the best individual treatment strategy.

\section{Non-vitamin $K$ antagonist oral anticoagulant in the elderly}

For decades, the VKA Warfarin has traditionally represented the cornerstone for stroke prevention in AF patient, thanks to its undoubted efficacy, despite important limits (Table 1). ${ }^{19}$ Such limits, which are more obvious in the elderly, in relation to changes in body composition, pharmacokinetics, as well as the frequent polypharmacy and frailty syndrome, unfortunately decrease Warfarin effectiveness and safety. ${ }^{20,21}$

Recently, some non-vitamin $\mathrm{K}$ antagonist oral anticoagulants (NOACs) have been developed, in order to overcome the main limitations of warfarin. Four randomized controlled trials (RCTs), each of them carried out with a different drug, have showed either non inferiority or superiority of NOACs in the prevention of stroke and systemic embolism (SE) in the general population, with significantly reduced risk of intracranial bleeding, determining a net clinical benefit compared with warfarin. ${ }^{22-}$ ${ }^{25}$ The subgroup analysis about net clinical benefit provided similar results in patients aged $\geq 75$ years, compared to general population, although, as expected, the absolute incidence of stroke, SE and major bleeding was higher in subjects aged $\geq 75$ years than in the younger population. ${ }^{26}$ Taking together, the NOACs have been proven effective and safe in comparison with warfarin in the elderly. However, incidence of major bleedings resulted heterogeneous between the different therapeutic agents, as reported in the trials described below.

Table 1. Main limitations of warfarin therapy in elderly patients.

\author{
Unpredictable response \\ Slow onset and slow cessation of therapeutic effect \\ Narrow therapeutic window \\ Difficulties in ensuring adequate time in therapeutic range \\ Several interactions with food \\ Several interactions with drugs \\ Need for routine monitoring of coagulation parameters with frequent dosage adjustments
}




\section{Direct thrombin inhibitors}

\section{Dabigatran}

The Randomized Evaluation of LongTerm Anticoagulation Therapy (RE-LY) trial compared dabigatran with warfarin in 18,113 patients with NVAF, presenting a mean $\mathrm{CHADS}_{2}$ score of 2.2 and a median age of 71.2 years. Forty percent of patients in the RE-LY trial were aged $\geq 75$ years. ${ }^{22}$ In the whole trial population, dabigatran 150 $\mathrm{mg}$ (but not $110 \mathrm{mg}$ ) twice daily (BID) $v s$ warfarin showed better results in terms of reduction of stroke and SE (HR 0.66, $\mathrm{P}<0.001)$ and comparable effects in major bleeding ( $\mathrm{HR}$ 0.93, $\mathrm{P}=0.81$ ). The lower dose of dabigatran showed a $20 \%$ reduction of relative risk of major bleeding, compared to Warfarin, in the presence, however of a comparable thromboembolic risk. Both doses of dabigatran reduced the rate of $\mathrm{ICH}$, compared with warfarin. ${ }^{22,27}$

Specifically, in patients aged $\geq 75$ years, Dabigatran $150 \mathrm{mg}$ bid performed similarly to warfarin in reducing stroke and SE, but at the expense of an age-related increase in the risk of major extracranial bleeding. In fact, as compared with warfarin, the risk of major bleedings associated to Dabigatran $150 \mathrm{mg}$ bid was lower in patients aged $<75$ years (HR 0.7; $\mathrm{P}<0.001$ ) and higher in those aged $\geq 75$ years (HR 1.18; $\mathrm{P}<0.001$ ), whereas the reduction in major bleeding, evident in the overall population treated by Dabigatran $110 \mathrm{mg}$ bid, was lost in the subgroup aged $\geq 75$ years. The risk of $\mathrm{ICH}$ was steadily reduced by dabigatran $v s$ warfarin, irrespectively of drug dose and patient's age. On the contrary, Dabigatran $150 \mathrm{mg}$ bid was associated with increased gastrointestinal bleeding in patients aged $\geq 75$ years. ${ }^{28,29}$ Since about $80-85 \%$ of dabigatran is eliminated by kidneys and elderly patients often have impaired renal function, it is advisable to pay attention to the drug dosage: indeed, a moderate kidney failure (creatinine clearance $30-50 \mathrm{~mL} / \mathrm{min}$ ) determines an increase of approximately twice in exposure to this drug. Notably, Dabigatran is contraindicated when creatinine clearance is $<30 \mathrm{~mL} / \mathrm{min}$. The FDA, but not EMA, suggests prescribing Dabigatran 75 $\mathrm{mg}$ bid if creatinine clearance is $30 \mathrm{~mL} / \mathrm{min}$ and the patient is contemporarily taking dronedarone or systemic ketoconazole. A lower dose of dabigatran (i.e., $110 \mathrm{mg}$ instead of $150 \mathrm{mg}$ bid) should be considered for patients aged 75-79 years. The same dosage is recommended by EMA, but not by the FDA, for patients aged $>80$ years. ${ }^{30,31}$ Data from real world registries have demonstrated a similar effect of dabigatran vs warfarin across the age subgroups: decreased risk of SE, ischemic stroke and myocardial infarction, without evidence of an increased risk of harm outcomes with the exception of gastrointestinal hemorrhage. ${ }^{32}$ A large single-center cohort of real-life Italian population with NVAF at high thromboembolic and hemorrhagic risk has demonstrated a safety profile of both dosages of dabigatran regarding major or fatal bleeding: among patients with a mean age of $64.9 \pm 8.8$ years $\left(\mathrm{CHA}_{2} \mathrm{DS}_{2}\right.$ Vasc Score $\geq 3$ in $94.3 \%$ and HAS-BLED $\geq 3$ in $59.7 \%$ ) taking Dabigatran $150 \mathrm{mg}$ and among patients with mean age of $73.9 \pm 7.5$ years $\left(\mathrm{CHA}_{2} \mathrm{DS}_{2}\right.$ Vasc Score $\geq 3$ in $73.4 \%$ and HAS-BLED $\geq 3$ in $87.4 \%$ ) taking dabigatran $110 \mathrm{mg}$, no gastrointestinal bleedings occurred, but one case of subarachnoid hemorrhage in the former group and one case of ischemic stroke and one of bladder bleeding in the latter group. ${ }^{33}$ In a recently published meta-analysis on observational cohort studies, dabigatran was comparable with warfarin in preventing ischemic stroke among patients with NVAF, with a lower risk for ICH relative to warfarin, but a greater risk for gastrointestinal bleeding, particularly among the elderly. Indeed, while there was no evidence for an increased risk of gastrointestinal bleeding with dabigatran in studies of younger populations, actually there was an increased risk of $\approx 50 \%$ for dabigatran $150 \mathrm{mg}$ versus warfarin in studies of older populations with mean/median age $\geq 75$ years. ${ }^{34}$

\section{Direct factor Xa inhibitors}

\section{Rivaroxaban}

The Rivaroxaban Once Daily Oral Direct Factor Xa Inhibition Compared with Vitamin $K$ Antagonism for Prevention of Stroke and Embolism Trial in Atrial Fibrillation (ROCKET AF) multicenter RCT compared Rivaroxaban $20 \mathrm{mg}$ once/day (OD) (15 mg od in patients with creatinine clearance $15-49 \mathrm{~mL} / \mathrm{min}$ ) with Warfarin in 14,264 AF patients with a median age of 73 years and a mean $\mathrm{CHADS}_{2}$ score of 3.5. Enrolled patients were older and with a higher degree of comorbidities than all other trials on NOACs. Thirty-eight percent of patients in the trial were aged $\geq 75$ years. ${ }^{23}$ Rivaroxaban was found noninferior to warfarin in terms of efficacy (reduction of stroke/SE) and safety (reduction of major bleeding), with the exception of gastrointestinal bleedings, that resulted higher with rivaroxaban. In patients aged $\geq 75$ years, Rivaroxaban has fostered a reduction of stroke and SE similarly to warfarin (HR 0.8; $\mathrm{P}=0.3$ ), with a comparable risk of major bleeding. The risk of ICH was lower with rivaroxaban $(\mathrm{HR}=0.67)$, in absence of significant age-related modifications. ${ }^{35}$ In 2015, real world data presented at the American Geriatrics Society Annual Scientific Meeting showed that the rates of major bleeding and fatal outcomes in elderly patients treated in routine clinical practice generally are consistent with those reported in Phase 3 clinical trials. Particularly, of the 31,883 patients using rivaroxaban, an incidence of major bleeding was observed at 2.85 per 100 person-years, with 74.1 percent of these events occurring in those 75 years of age and older. Gastrointestinal bleeding was the most common bleeding event in all age groups, followed by ICH. Fatal outcomes as a result of major bleeding were low (mean age of death was 82.1 years) and mainly occurred in patients with comorbidities. ${ }^{36}$ In the noninterventional study of Rivaroxaban for the prevention of stroke in patients with $\mathrm{AF}$ (XANTUS) study, which assessed the safety and efficacy of rivaroxaban in routine, real-world clinical practice, the percentage of patients aged $\geq 75$ years was $37 \%$, comorbidities were common and the mean $\mathrm{CHADS}_{2}$ score was 2.0, while the mean $\mathrm{CHA}_{2} \mathrm{DS}_{2}$-VASc score was 3.4. In such study, incidence of major bleedings was lower than in ROCKET AF trial (with similar rate for $\mathrm{ICH}$ ), although the event rate increased with age, reaching 3.2 events per 100 patient-years in patients aged $>75$ years. Similarly, the rates for symptomatic thromboembolic events was lower than in ROCKET AF, but increased with age, reaching 2.3 events per 100 patient-years in patients aged $>75$ years. $^{37}$

\section{Apixaban}

The Apixaban for Reduction in Stroke and Other Thromboembolic Events in Atrial Fibrillation (ARISTOTLE) trial included 18,201 NVAF patients with a median age of 70 years and a mean $\mathrm{CHADS}_{2}$ score of 2.1. This trial showed that Apixaban $5 \mathrm{mg}$ bid (2.5 $\mathrm{mg}$ bid if any two of three conditions were present: age $\geq 80$ years, serum creatinine $\geq 1.5 \mathrm{mg} / \mathrm{dL}$ or $\geq 133 \mu \mathrm{mol} / \mathrm{L}$ and body weight $<60 \mathrm{~kg}$ ) was non-inferior and maybe superior to warfarin in preventing stroke/SE (HR 0.79; $\mathrm{P}<0.001$ ), and in reducing major bleeding (HR 0.69; $\mathrm{P}<0.001)$ and $\mathrm{ICH} .{ }^{24}$

In patients aged $\geq 75$ years $(31 \%$ of the whole study population), apixaban was associated with a reduction of both incidence of stroke/se and rate of major bleedings similarly to warfarin ( $\mathrm{HR} 0.64, \mathrm{P}=0.6$; HR $0.71, \mathrm{P}=0.11$, respectively). ${ }^{38}$ The advantage of apixaban, regarding to major bleedings, was even greater in patients with renal dysfunction. Furthermore, this drug 
has been proven more beneficial than warfarin in decreasing the risk of digestive bleedings. By summarizing, the efficacy and safety of apixaban was consistent across all subgroups, including elderly patients. ${ }^{38,39}$

In the Apixaban Versus Acetylsalicylic Acid to Prevent Stroke in Atrial Fibrillation Patients Who Have Failed or Are Unsuitable for Vitamin $K$ Antagonist Treatment (AVERROES) trial, apixaban (5 $\mathrm{mg}$ bid or $2.5 \mathrm{mg}$ bid, basing on criteria already established for the ARISTOTLE) was compared with aspirin (81-324 mg od) in AF patients unsuitable for Warfarin. Such design stemmed from previous findings showing that aspirin was able to promote a $20 \%$ reduction of stroke, compared to placebo. AVERROES included 5,599 AF patients with a median age of 70 years and a mean $\mathrm{CHADS}_{2}$ score of 2. In this study, the rate of stroke/SE was significantly reduced with apixaban, compared to aspirin (HR $0.45 \mathrm{P}<0.001$ ), with similar effects on major bleedings or ICH. These results were not influenced by age and suggest that apixaban should be considered a viable alternative, especially for elderly patients unsuitable for warfarin therapy. ${ }^{40} \mathrm{~A}$ sub-group analysis of the AVERROES trial indicates that older patients with AF are at particularly high risk of stroke if given aspirin and have substantially greater relative and absolute benefits from apixaban compared with younger patients with no greater risk of hemorrhage. Particularly, apixaban was more efficacious than aspirin for preventing strokes and systemic embolism in patients $\geq 85$ years (HR 0.14, 0.02-0.48) compared with younger patients (HR 0.50, 0.35-0.69). Major hemorrhage was higher in patients $\geq 85$ years compared with younger patients but similar with apixaban versus aspirin with no significant treatment-by-age interaction. ${ }^{41}$ In a large cohort of patients with non-valvular AF, assessing the real-world effectiveness and safety of dabigatran, rivaroxaban, and apixaban, in comparison with warfarin, apixaban was associated with better effectiveness and safety than warfarin. Particularly, while dabigatran $150 \mathrm{mg}$ and rivaroxaban were both related to a higher risk of gastrointestinal bleeding, apixaban was related to a not significant numerically lower risk of gastrointestinal bleeding. Such finding may explain why apixaban was found to be prescribed for many elderly patients in such cohort. ${ }^{42}$

\section{Edoxaban}

Among all RCTs on NOACs, the Effective Anticoagulation with Factor Xa Next Generation in Atrial Fibrillation (ENGAGE AF) trial involved the largest number of elderly patients. In fact, out of the 21,105 patients enrolled in this study, $8474(40.2 \%)$ were aged $\geq 75$ years. In this trial, patients were randomized in 1:1:1 fashion at edoxaban $60 \mathrm{mg}$ od, edoxaban 30 $\mathrm{mg}$ od or warfarin, the latter up-titrated to a target INR between 2 and 3. The dosage of edoxaban was halved to $30 \mathrm{mg}$ if any of the following determinants were present at enrollment or happened during the study: creatinine clearance $\leq 50 \mathrm{~mL} / \mathrm{min}$; body weight $\leq 60 \mathrm{~kg}$; concomitant use of potent P-glycoprotein inhibitors. ${ }^{25}$ Twenty-five percent of enrolled patients met criteria for dose reduction with higher prevalence in the $\geq 75$ years subgroup $(10.4 \%, 18.2 \%$ and $41.2 \%$ of patients, respectively, in $<65,65$ 74 and $\geq 75$ year age groups). Moderate renal dysfunction was the main determinant of dose reduction in patients aged $\geq 75$ years. Data analysis of ENGAGE-AF showed that, in patients aged $\geq 75$ years, the incidence of stroke/SE was similar, regardless of treatment with edoxaban or warfarin (HR 0.83 $\mathrm{P}=0.84$ ), while major bleeding and $\mathrm{ICH}$ were significantly reduced with edoxaban (HR 0.83 and 0.4, respectively).

Although in the whole trial population the reduced edoxaban regimen, compared to warfarin, was associated with higher rates of ischemic stroke but lower incidence of gastrointestinal bleeding, in the subgroup of elderly, edoxaban $30 \mathrm{mg}$ od (corresponding to average plasma concentrations of the drug and of the mean anti FXa activity decreased by $30-40 \%$ and $20-40 \%$, respectively) showed similar efficacy to warfarin in preventing stroke/SE with the advantage of greater reduction in major bleeding $(\mathrm{P}<0.001) .{ }^{43}$ In the elderly, particularly in those with renal dysfunction, the need to individualize the dosage should be taken into due consideration, since Edoxaban presented a wider therapeutic window for thromboembolism than for major bleedings in this class of age.

\section{Head-by-head comparison}

A recent meta-analysis of eleven RCTs, that included all four NOACs and analyzed data of patients aged $>75$ years, both in the setting of AF and venous thromboembolism, has shown that every NOAC was at least comparable to VKA in terms of effectiveness in reducing the risk of stroke/SE. In the elderly, the risk of stroke/SE was significantly lowered by dabigatran $150 \mathrm{mg}$ bid (OR 0.66) and apixaban (OR 0.7). Likewise, in this meta-analysis, a relevant reduction in the risk of major bleeding was found with apixaban (OR 0.63) and edoxa- ban $60 \mathrm{mg}$ and $30 \mathrm{mg}$ (OR 0.81 and 0.46, respectively), in comparison with VKA. As noteworthy, the risk of major bleeding was characterized by only a non-significant increase with dabigatran $150 \mathrm{mg}$ in this age group (OR 1.18), while the risk of digestive bleeding has been proven greater with dabigatran $150 \mathrm{mg}$ (OR 1.78) and $110 \mathrm{mg}$ (OR 1.4), in the absence of corresponding data for the other NOACs. Regarding to ICHs in elderly patients, a significant risk reduction was noticed, in comparison with VKA, in case of use of dabigatran $150 \mathrm{mg}$ (OR 0.43) and $110 \mathrm{mg}$ (OR 0.36) and Apixaban (OR 0.38). Finally, as compared to VKA, Rivaroxaban has been found effective to reduce fatal bleedings (OR 0.53) and Apixaban to lower clinically relevant bleedings (OR 0.64). With the remaining NOACs, the rate of fatal or clinically relevant bleedings was similar to that of VKA. ${ }^{44}$

In Table 2, comparative data about efficacy and safety of the four NOACs vs warfarin, as a function of patient's age, are reported. It should be pointed out that data about gastrointestinal bleedings in the elderly are only available for dabigatran and edoxaban and not for other NOACs.

\section{Knowledge gaps and discussion}

Anticoagulant therapy in the elderly is commonly considered a double-edged sword, because the simultaneous presence of frailty, comorbidity, polypharmacy and dementia reduce the resilience of the patient, with a greater vulnerability to hemorrhagic events. Thus, the higher the risk of thromboembolism the lower the percentage of patients undergoing anticoagulant therapy: this might be claimed the therapeutic paradox of the elderly.

Nevertheless, retrospective observational studies have highlighted that in old patients the use of VKA is associated with a reduction in overall mortality, regardless of health conditions and functional state. ${ }^{45}$ Particularly, in elderly AF patients, even if cognitively impaired and/or functionally dependent, OAT is associated with reduced mortality and lower occurrence of ischemic stroke. ${ }^{46}$ Thus, the overall benefit of OAT seems to outweigh the risks, even in elderly patients at increased risk of bleeding or fall. ${ }^{47}$ The NOACs emerged as an attractive alternative to Warfarin in elderly patients: the evidence of a net clinical benefit, mainly determined by the reduction in ICH, has lead recent international guidelines to suggest their use as first choice in patients with NVAF. ${ }^{10,48,49}$

However, some conceptual and practi- 
Table 2. Summary of efficacy and safety data of NOACs $v \boldsymbol{s}$ warfarin expressed as O.R. ${ }^{46}$

\begin{tabular}{|c|c|c|c|c|c|c|c|c|c|c|}
\hline \multirow[b]{2}{*}{ Age } & \multirow{2}{*}{$\begin{array}{l}\text { Stroke } \\
\geq 75\end{array}$} & \multirow{2}{*}{$\begin{array}{l}\text { SE } \\
<75\end{array}$} & \multicolumn{2}{|c|}{ Major Bleeding } & \multicolumn{2}{|c|}{ Gastroint. Bleeding } & \multicolumn{2}{|c|}{ ICH } & \multicolumn{2}{|c|}{ Fatal Bleeding } \\
\hline & & & $\geq 75$ & $<75$ & $\geq 75$ & $<75$ & $\geq 75$ & $<75$ & $\geq 75$ & $<75$ \\
\hline $\begin{array}{l}R E-L Y \\
\text { Dabigatran } 150 \mathrm{mg} \text { vs VKA } \\
\text { Dabigatran } 110 \mathrm{mg} \text { us VKA }\end{array}$ & $\begin{array}{l}0.66 \\
0.88\end{array}$ & $\begin{array}{l}0.64 \\
0.93\end{array}$ & $\begin{array}{c}1.2 \\
1.03\end{array}$ & $\begin{array}{l}0.73 \\
0.65\end{array}$ & $\begin{array}{l}1.78 \\
1.4\end{array}$ & $\begin{array}{l}1.19 \\
0.83\end{array}$ & $\begin{array}{l}0.43 \\
0.36\end{array}$ & $\begin{array}{l}0.43 \\
0.34\end{array}$ & $\begin{array}{l}0.92 \\
0.73\end{array}$ & $\begin{array}{c}0.55 \\
0.5\end{array}$ \\
\hline $\begin{array}{l}\text { ROCKET AF } \\
\text { Rivaroxaban vs VKA }\end{array}$ & 0.8 & 0.95 & 1.15 & 0.92 & - & - & 0.88 & 0.52 & 0.53 & 0.48 \\
\hline $\begin{array}{l}\text { ARISTOTLE } \\
\text { Apixaban vs VKA }\end{array}$ & 0.71 & 0.85 & 0.65 & 0.73 & - & - & 0.38 & 0.5 & 0.8 & 0.67 \\
\hline $\begin{array}{l}\text { ENGAGE-AF TIMI } 48 \\
\text { Edoxaban } 60 \mathrm{mg} \text { vs VKA } \\
\text { Edoxaban } 30 \mathrm{mg} \text { vs VKA }\end{array}$ & $\begin{array}{l}0.81 \\
1.12\end{array}$ & $\begin{array}{l}0.93 \\
1.17\end{array}$ & $\begin{array}{l}0.81 \\
0.46\end{array}$ & $\begin{array}{l}0.76 \\
0.49\end{array}$ & $\begin{array}{c}1.32 \\
-\end{array}$ & - & $\begin{array}{c}0.4 \\
-\end{array}$ & $\begin{array}{c}0.42 \\
-\end{array}$ & $\begin{array}{c}0.46 \\
-\end{array}$ & $\begin{array}{c}0.62 \\
-\end{array}$ \\
\hline
\end{tabular}

cal aspects merit to be pointed out. Bleeding risk is one of the most feared consequences of OAT in the elderly (due to changes in body composition, with a reduction in lean body mass, renal dysfunction, frailty, comorbidities, polypharmacy, dementia and risk of falls) and, in case of NOACs, is exacerbated by the difficulty of monitoring their anticoagulant activity ${ }^{48}$ and by the concerns about availability of antidotes. The recently introduced idarucizumab neutralizes the effects of dabigatran, thus permitting the use of such NOAC even in patients at higher risk of bleeding. On the contrary, no antidotes for Factor Xa inhibitors are available yet, although andexanet alpha is very promising in this regard. Fortunately, NOACs have a short half-life (between 5 and 17 hours), much lower than that of Warfarin (36-42 h)..$^{50-52} \mathrm{ICH}$ are one of the most devastating hemorrhagic complications, given the high risk of mortality and severe disability. All NOACs are very beneficial in reducing the ICH risk, when compared to Warfarin, and interestingly this benefit is maintained in the elderly, in spite of their increased susceptibility to falls and head trauma. ${ }^{10,53}$

Despite the absence of food limitations, some possible pharmacological interactions can promote adverse events by NOACs. ${ }^{45}$ For example, the association with drugs, which are strong inducers, or inhibitors of P-gp can significantly reduce or enhance the plasma concentration of NOACs. As demonstrated by post-hoc analyses of the major RCTs, polypharmacy was frequent in the population included in the ARISTOTLE trial, and was associated with a higher comorbidity and mortality, as well as a higher rate of thromboembolic and major bleeding events. Although apixaban was more effective and at least as safe as warfarin, regardless of the number of other medications, its benefits tended progres- sively to reduce in function of the number of concomitantly prescribed drugs. ${ }^{54}$ Similarly, in the re-analysis of the ROCKET-AF trial, patients taking more than 10 drugs showed a non-significant trend of increased risk of major and minor bleeding, in the absence of stroke/SE modifications, compared to patients taking up to 4 drugs. ${ }^{55}$

Moreover, patients on multidrug therapy have been shown to adhere less to therapy regimen than patients on little drug therapy. Contrary to Warfarin, for which about $36 \%$ of the patients have been shown not taking more than $20 \%$ of the planned doses, ${ }^{56}$ all NOACs have demonstrated a good therapeutic adherence in over $85 \%$ of patients in real world clinical practice. ${ }^{57,58}$ This is particularly important in patients with dementia, ${ }^{59}$ which are known to poorly adhere to therapy and require additional treatment strategies, involving also caregivers, in order to ensure adequate surveillance of both adherence and side effects. ${ }^{10,53}$ In this setting, NOACs should be preferred to warfarin.

In conclusion, current knowledge favors the use of NOACs in elderly patients. However, available data mainly derive from RCTs, whose main limitation is not having enrolled the most sick patients, such as those with frailty, important changes in functional status and serious comorbidities. Future studies on NOACs involving this type of patients should be encouraged. In the meantime, benefits and risks of NOACs have to be carefully weighted, always bearing in mind that elderly patients are at higher risk of thromboembolism. By such point of view, it would be advisable that a comprehensive geriatric assessment is carried out. No current studies have specifically implemented a comprehensive geriatric assessment in verifying safety and efficacy of NOACs. However, it seems conceivable that several already validated functional, cognitive and frailty scales can be employed at such purpose. Together with assessment of renal function and evaluation of specific clinical context, they should address the NOAC with the best efficacy and safety profile for a particular old patient. In such a double-edged sword, a multi-dimensional evaluation might improve patients' and care givers' compliance.

\section{References}

1. Feign VL, Forouzanfar $\mathrm{MH}$, Krishamurthi R, et al. Global and regional burden of stroke during 19902010 findings from the Global Burden of Disease Study 20010. Lancet 2014; 383:245-54.

2. Go AS, Hylek EM, Philips KA, et al. Prevalence of diagnosed atrial fibrillation in adults: national implications for rhythm management and stroke prevention: the anticoagulation and risk factors in atrial fibrillation (ATRIA) study. JAMA 2001;285:2370-5.

3. Lloyd-Jones DM, Wang TJ, Leip EP, et al. Lifetime risk for development of atrial fibrillation: the Framingham Heart Study. Circulation 2004;110:1042-6.

4. Miyasaka Y, Barnes ME, Gersh BJ, et al. Secular trends in incidence of atrial fibrillation in Olmsted County Minnesota 1980 to 2000 and implications on the projections for future prevalence. Circulation 2006;114:119-25.

5. Kirchhof P, Benussi S, Kotecha D, et al. 2016 ESC Guidelines for the management of atrial fibrillation developed in collaboration with EACTS The Task Force for the management of atrial fibrillation of the European Society of Cardiology (ESC) Developed with the special contribution of the European 
Heart Rhythm Association (EHRA) of the ESC Endorsed by the European Stroke Organisation (ESO). Eur Heart J 2016 [Epub ahead of print].

6. Lip GY, Clementy N, Pericart L, et al. Stroke and major bleeding risk in elderly patients aged $\geq 75$ years with atrial fibrillation: the Loire Valley atrial fibrillation project. Stroke 2015;46:143-50.

7. Turagam MH, Velagapudi P, Flaker GC. Stroke prevention in the elderly atrial fibrillation patient with comorbid conditions: focus on non-vitamin K antagonist anticoagulants. Clin Interv. Aging 2015;10:1431-44.

8. Annoni G, Mazzola P. Real-world characteristics of hospitalized frail elderly patients with atrial fibrillation: can we improve the current prescription of anticoagulants?. J Ger Cardiol 2016;13: 226-32.

9. Atrial Fibrillation Investigators. Risk factors for stroke and efficacy of antithrombotic therapy in atrial fibrillation: analysis of pooled data from five randomized controlled trials. Arch Intern Med 1994;154:1449-57.

10. Andreotti F, Rocca B, Husted S, et al. Antithrombotic therapy in the elderly: expert position paper of the European Society of Cardiology Working Group on Thrombosis. Eur Heart J 2015 [Epub ahead of print].

11. Perera V, Bajorek BV, Matthews S, Hilmer SN. The impact of frailty on the utilisation of antithrombotic therapy in older patients with atrial fibrillation. Age Ageing 2009;38:156-62.

12. Hart RG, Pearce LA, Aguilar MI. Metaanalysis: antithrombotic therapy to prevent stroke in patients who have nonvalvular atrial fibrillation. Ann Intern Med 2007;146:857-67.

13. Di Pasquale G, Mathieu G, Maggioni AP, et al. Current presentation and management of 7148 patients with atrial fibrillation in cardiology and internal medicine hospital centers: The ATA AF study. Int J Cardiol 2013;167:2895-903.

14. Gussoni G, Di Pasquale G, Vescovo G, et al. Decision making for oral anticoagulants in atrial fibrillation: the ATA-AF study. Eur J Intern Med 2013;24:324-32.

15. Olesen JB, Lip GY, Lindhardsen J, et al. Risks of thromboembolism and bleeding with thromboprophylaxis in patients with atrial fibrillation: A net clinical benefit analysis using a 'real world' nationwide cohort study. Thromb Haemost 2011;106:739-49.

16. Singer DE, Chang Y, Fang MC, et al. The net clinical benefit of warfarin anticoagulation in atrial fibrillation. Ann Intern Med 2009;151:297-305.
17. Bo M, Sciarrillo I, Li Puma F, et al. Effects of oral anticoagulant therapy in medical inpatients $\geq 65$ years with atrial fibrillation. Am J Cardiol 2016;117: 590-5.

18. Poli D, Antonucci E, Testa S, et al. Gender differences of bleeding and stroke risk in very old atrial fibrillation patients on VKA treatment: results of the EPICA study on the behalf of FCSA (Italian Federation of Anticoagulation Clinics). Thromb Res 2013;131:12-6.

19. Robert-Ebadi H, Le Gal G, Righini M. Use of anticoagulants in elderly patients: practical recommendations. Clin Interv Aging 2009;4:165-77.

20. Garcia D, Regan S, Crowther M, et al. Warfarin maintenance dosing patterns in clinical practice: implications for safer anticoagulation in the elderly population. Chest 2005; 127:2049-56.

21. Mant J, Hobbs FD, Fletcher K, et al. Warfarin versus aspirin for stroke prevention in an elderly community population with atrial fibrillation (the Birmingham Atrial Fibrillation Treatment of the Aged Study, BAFTA): a randomised controlled trial. Lancet 2007;370:493-503.

22. Connolly SJ, Ezekowitz MD, Yusuf S, et al. Dabigatran versus warfarin in patients with atrial fibrillation. N Engl J Med 2009; 361:1139-51.

23. Patel MR, Mahaffley KW, Garg J, et al. Rivaroxaban versu warfarin in nonvalvular atrial fibrillation. N Engl J Med 2011;365:883-91.

24. Granger CB, Alexander JH, Mc Murray $\mathrm{JJ}$, et al. Apixaban versus warfarin in patients with atrial fibrillation. N Engl J Med 2011;365:981-92.

25. Giugliano RP, Ruff CT, Braunwald E, et al. Edoxaban versus warfarin in patients with atrial fibrillation. N Engl J Med 2013;369:2093-104.

26. Kundu A, Sardar P, Chatterrje S, Aronow WS. Minimizing the risk of bleeding with NOACs in the elderly. Drugs Aging 2016;33:491-500.

27. Huisman MV, Lip GY, Diener HC, et al. Dabigatran etexilate for stroke prevention in patients with atrial fibrillation: resolving uncertainties in routine practice. Thromb Haemost 2012;107:838-47.

28. Eikelboom JW, Wallentin L, Connolly SJ, et al. Risk of bleeding with 2 doses of dabigatran compared with warfarin in older and younger patients with atrial fibrillation: an analysis of the randomized evaluation of long-term anticoagulant therapy (RE-LY) trial. Circulation 2011;123:2363-72.

29. Brunetti L, Chen C, White J. Dabigatran for stroke prevention in nonvalvular atrial fibrillation: focus in the geriatric pop- ulation. Consult Pharm 2014;29:169-78.

30. Hijazi Z, Hohnloser SH, Oldgren J, et al. Efficacy and safety of dabigatran compared with warfarin in relation to baseline renal function in patients with atrial fibrillation: a RE-LY (Randomized Evaluation of Long-term Anticoagulation Therapy) trial analysis. Circulation 2014;129:961-70.

31. Reilly PA, Lehr T, Haertter S, et al. The effect of dabigatran plasma concentrations and patient characteristics on the frequency of ischemic stroke and major bleeding in atrial fibrillation patients: the RE-LY Trial (Randomized Evaluation of Long-Term Anticoagulation Therapy). J Am Coll Cardiol 2014;63:321-8.

32. Lauffenburger JC, Farley JF, Gehi AK, et al. Effectiveness and safety of dabigatran and warfarin in real-world US patients with non-valvular atrial fibrillation: a retrospective cohort study. J Am Heart Assoc 2015;4:4.

33. Russo V, Bianchi V, Cavallaro C, et al. Efficacy and safety of dabigatran in a "real-life" population at high thromboembolic and hemorrhagic risk: data from Monaldi Care registry. Eur Rev Med Pharmacol Sci 2015;19:3961-7.

34. Romanelli RJ, Nolting L, Dolginsky M, et al. Dabigatran versus warfarin for atrial fibrillation in real-world clinical practice a systematic review and meta-analysis. Circ Cardiovasc Qual Outcomes 2016;9:126-34.

35. Fox KA, Piccini JP, Wojdyla D, et al. Prevention of stroke and systemic embolism with rivaroxaban compared with warfarin in patients with nonvalvular atrial fibrillation and moderate renal impairment. Eur Heart J 2011;32: 2387-94.

36. The American Geriatrics Society. 2015 Annual Scientific Meeting. National Harbor, MD, May 2015.

37. Camm AJ, Amarenco P, Haas S, et al. XANTUS: a real-world, prospective, observational study of patients treated with rivaroxaban for stroke prevention in atrial fibrillation. Eur Heart J 2016; 37:1145-53.

38. Halvorsen S, Atar D, Yang H, et al. Efficacy and safety of apixaban compared with warfarin according to age for stroke prevention in atrial fibrillation: observations from the ARISTOTLE trial. Eur Heart J 2014;35:1864-72.

39. Hohnloser SH, Hijazi Z, Thomas L, et al. Efficacy of apixaban when compared with warfarin in relation to renal function in patients with atrial fibrillation: insights from the ARISTOTLE trial. Eur Heart J 2012;33:2821-30.

40. Connolly SJ, Eikelboom J, Joyner C, et 
al. Apixaban in patients with atrial fibrillation. N Engl J Med 2011;364:806-17.

41. Ng KH, Shestakovska O, Connolly SJ, et al. Efficacy and safety of apixaban compared with aspirin in the elderly: a subgroup analysis from the AVERROES trial. Age Ageing 2016;45:77-83.

42. Yao X, Abraham NS, Sangaralingham LR, et al. Effectiveness and safety of dabigatran, rivaroxaban, and apixaban versus warfarin in nonvalvular atrial fibrillation. J Am Heart Assoc 2016;5: e003725.

43. Kato ET, Giugliano RP, Ruff CT, et al. Efficacy and safety of edoxaban in elderly patients with atrial fibrillation in ENGAGE AF-TIMI 48 Trial. J Am Heart Assoc 2016;5:e03432.

44. Sharma M, Cornelius VR, Patel JP, et al. Efficacy and harms of direct oral anticoagulants in the elderly for stroke prevention in atrial fibrillation and secondary prevention of venous thromboembolism; systematic review and meta-analysis. Circulation 2015;132:194-204.

45. Pilotto A, Gallina P, Copetti M, et al. on behalf of MPI_AGE Project Investigators. Warfarin treatment and allcause mortality in community-dwelling older patients with atrial fibrillation: a retrospective observational study. J Am Geriatr Soc 2016;64:1416-24.

46. Bo M, Li Puma F, Badinella Martini M, et al. Effects of oral anticoagulant therapy in older medical in-patients with atrial fibrillation: a prospective cohort observational study. Aging Clin Exp Res 2016 [Epub ahead of print].

47. McGrath ER, Go AS, Chang Y, et al. Use of oral anticoagulant therapy in older adults with atrial fibrillation after acute ischemic stroke. J Am Geriatr Soc 2017;65:241-8.

48. Heidbuchel H, Verhamme P, Alings M, et al. Updated European Heart Rhythm Association Practical Guide on the use of non-vitamin $\mathrm{K}$ antagonist anticoagulants in patients with non-valvular atrial fibrillation. Europace 2015;17:1467-507.

49. Zarraga IG, Kron J. Oral anticoagulation in elderly adults with atrial fibrillation: integrating new new options with old concepts. J Am Geriatr Soc 2013;61: 143-50.

50. Bibas L, Levi M, Touchette J, et al. Implications of frailty in elderly patients with electrophysiological conditions. J Am Coll Cardiol EP 2016;2:288-94.

51. Pollack CV, Reilly PA, Eikelboom JW, et al. Idarucizimab for Dabigatran reversal. N Engl J Med 2015;373:511-20.

52. Connolly SJ, Milling TJ, Eikelboom J W, et al. Andexanet alfa for acute major bleeding associated to Factor $\mathrm{Xa}$ Inhibitors. N Engl J Med 2016;375: 1131-41.

53. Kundu A, Sardar P, Chatterrje S, Aronow WS. Minimizing the risk of bleeding with NOACs in the elderly. Drugs Aging 2016;33:491-500.
54. Focks JJ, Brouwer MA, Wojdyla DM, et al. Polypharmacy and effects of apixaban versus warfarin in patients with atrial fibrillation: post hoc analysis of the ARISTOTLE trial. BMJ 2016;353:i2868.

55. Piccini JP, Hellkamp AS, Washam JB, et al. Polypharmacy and the efficacy and safety of rivaroxaban versus warfarin in the prevention of stroke in patients with nonvalvular atrial fibrillation. Circulation 2016;133:352-60.

56. Kakkar AK, Mueller I, Bassand JP, et al. Risk profiles and antithrombotic treatment of patients newly diagnosed with atrial fibrillation at risk of stroke: perspectives from the international, observational, prospective GARFIELD registry. PLoS One 2013;8:e63479.

57. Schulman S, Shortt B, Robinson M, Eikelboom JW. Adherence to anticoagulant treatment with dabigatran in a real-world setting. J Throm Haemost 2013;11:1295-9.

58. Al-Khalili F, Lindstrom C, Benson L. Adherence to anticoagulant treatment with apixaban and rivaroxaban in a realworld setting. Clin Trial Regul Science Cardiol 2016;18:1-4.

59. Beata JP, Lomper K, Alberska L, et al. Cognitive function and adherence to anticoagulation treatment in patients with atrial fibrillation. J Ger Cardiol 2016;13:559-65. 